\title{
Study on Inheritance and Innovation of Henan Nanyang Pyrograph Craft in Costume Design
}

\author{
$\mathrm{Na} \mathrm{Li}$ \\ Huanghe Science and Technology College \\ Zhengzhou, China
}

\begin{abstract}
Based on the background of economic zone construction in the Central Plains, this paper conducts a stable and orderly investigation under the guidance of the dominant idea of "the rise of Central Plains". This paper focuses on the analysis of the inheritance status of Henan Nanyang pyrograph craft, and the study on the innovative design of it in costume. At present, with the development of the market and the change of fashion, Henan Nanyang pyrograph craft is also facing many problems in the inheritance and development like most traditional crafts in China. The production and application of traditional techniques are facing certain difficulties, in the bottleneck period of development. This state makes the traditional craftsmen in Henan generally aware of the problems that the brand awareness is not strong, the application value is not high, the products are mid-low-end positioned, the competitive advantage is difficult to maintain, and the lack of talent leads to poor independent innovation, which also affects the design upgrading of subsequent products of traditional craft.
\end{abstract}

Keywords - traditional craft; pyrograph; innovation; costume

\section{INTRODUCTION}

The traditional handicrafts make an important part of the cultures of all countries in the world, an excellent cultural heritage of a country and a nation. In recent years, the traditional handicraft in the global context are near extinction due to the impact of modern lifestyles, at the same time, the image of traditional handicraft regenerate in modern cultural and art products all over the world. How to inherit traditional handicrafts in the human civilization, and how to introduce make traditional handicrafts into the contemporary life and culture, are the problems that the folk craftsmen, folk handicraft scholars, modern artists, modern design educators and even the relevant cultural departments of the government all over the world are thinking about.

\section{OVER VIEW OF PYROGRAPH CRAFT}

Nanyang pyrograph art is an art suiting both refined and popular tastes. Pyrograph art is a folk art, rooted in the folk, crystallizing the working people's intelligence. Its pyrographers are knowledgeable farmers who can write and paint, so the pyrograph itself is favored by farmers and also the upper community. In the early days of the liberation, Nanyang pyrograph stared development mainly from pyrographed chopsticks, which are essential tools for the oriental to eat. Wooden pyrographed chopsticks use holly medicine wood with fine texture and superb technology, whose property is cold and color is white. They present ivory yellow and have fragrance after soaking with sesame oil, which contributes to health. On the square-head chopsticks surface, the handpyrographed pictures by artisans are elegant and exquisite for appreciation, thus it has become the favorite of collectors. In modern times, the pyrograp develops to silk and rice paper, and forms art works similar to traditional Chinese painting. Today, pyrograph has become an elegant art work and gift for international friends, widely favored by people around the world.

\section{Protection Status, Problems And Causes Of The TRADITIONAL PYROGRAPH CRAFT IN HENAN ECONOMIC CONSTRUCTION}

\section{A. Investigation on the Protection Status of Pyrograph}

At present, China's intangible cultural heritage or traditional crafts, or face the crisis of decline or extinction, or blindly enter the market system, so the productive protection becomes the focus of many experts and scholars' attention. Although there are many doubts and worries about the concrete implementation of the productive protection, we have to admit that for the intangible cultural heritage with productive nature, to guarantee its survival and development in modern market is the only way to cure it. If it can not be linked with the market, and relies solely on the state's maintenance, ultimately it will be stiff or lost. Traditional handicrafts must be recognized and accepted by the market, own the driving force of survival and development, and form a virtuous circle to really achieve the purpose of protecting the craft.

\section{B. The Dilemma Faced by Pyrograph Craft Protection}

The word "traditional handicraft" is loaded with lots of special value information, which attracts more and more attention in the contemporary design field. Whether appreciate it or dislike it, whether continue or resist it, people frequently use this word and related terms in the positive, negative, commendatory or derogatory senses. Over the decade, on one hand, many scholars and researchers have been paying attention and initiating the work of handicraft culture rejuvenation, including holding nationwide symposiums, planning feature programme, field investigation and crossstrait research and communication; on the other hand, some people allege that handicraft culture rejuvenation is fantasy and can not be achieved in the contemporary time. 
IV. The INHeritance Principles AND Methods Of The PYROGRAPH CRAFT IN HENAN ECONOMIC CONSTRUCTION

\section{A. The Inheritance Principles of Pyrograph Craft}

1) Protection Principles of Traditional Handicraft and Inheritor: While paying attention to the inheritance and development of traditional folk handicrafts, it is necessary to enhance the ideological quality and cultural accomplishment of people who master the folk handicrafts, especially the young handicraftsmen, so as to make them recognize their own importance in handicraft culture heritage and development, and the burdens they bear. The government can create a good inheriting environment and cultural atmosphere for the survival of traditional handicrafts, improve the living conditions of inheritors through certain ways, and even the establish corresponding institutions to support and foster the development of traditional handicrafts, ridding inheritors of worries about life.

2) The principle of improving the craftsmen's working environment: Traditional craftsmen's working environment is relatively simple in general, for they do not care about the physical and psychological impact of working environment on them. Taking wood carving craft as an example, although modern wood carving masters' working environment has been greatly improved compared to the past, and many electrical machines are used as the production tools, in wood carving process, wood dust, chemicals like preservatives, insect repellants and chemical paint, electrical equipment operation errors, noise, etc. cause different degrees of injury to the practitioners. It is therefore important to improve the working environment of craftsmen and their safety awareness to ensure that they are in a safe working environment.

3) The principle of inheriting traditional handicraft culture: "The protection of traditional culture is not only to protect the material form, but also to protect its skills and cultural spirit." Therefore, in the inheritance of handicrafts, we should strengthen the collection and protection of traditional handicrafts. We can form a traditional handicraft art database by camera shooting, taking pictures, measuring, drawing, text records, etc., even if there is division of history in handicraft, the later generations can restore based on today's images, pictures and text data. However, the workload of this protection is numerous, and the time required is long, besides, it is an urgent work.

4) Principles of market adaptability: We should proceed to investigate and excavate traditional handicrafts, fully affirm their value, and activate the traditional handicrafts through various policies and measures, to make it more responsive to market demand. These policies include building a basic platform for the handicraft industry, supporting the development of excellent handicraft culture and sightseeing products, expanding the circulation base of the handicraft culture industry and expanding into the overseas market. Especially in the aspects of constructing basic platforms to develop traditional handicraft works that reflect the regional characteristics, the production and circulation of handicraft industry can be greatly supported by establishing a number of local craft producing area and opening display stores and so on. These policies and measures are designed to protect the traditional crafts to continue to be inherited and continue to progress by helping and supporting the development of handicraft industry.

\section{B. Feasibility Measures of Bpyrograph Craft}

1) The inheritance way of original style and traditional crafts: As traditional pyrograph handicrafts, still a lot of primitive style are maintained today, continuing the old ways of handicraft production and inheritance for thousands of years, stubbornly retaining the unique regional features of Central Plains, showing the history of the germination and development of handicraft like "living fossil" . So far, there are still many traditional crafts masters of various nations, who support the once glorious history lonely in honor. This is because the pyrograph art itself is the most unique and the most important traditional culture in traditional handicrafts. Therefore, we will continue to maintain the original historical style and craft techniques of pyrograph, strive to innovate, but not to subvert or damage the tradition.

2) Optimize the economic development strategy: The promotion of pyrograph art and the development of pyrograph industry can solve and help many unemployed youth and surplus labor force on re-employment. Pyrograph generates no noise or pollution, which is healthy and environmental protective. Pyrograph is not limited by age and cultural level, which easy to learn. The pyrograph industry can take the way of large-scale enterprise development, and can also take the way of family-style small-scale development. Only with the strong support of the government, with the media publicity in place can the people learn more about pyrograph, know the value of pyrograph art, so that the inheritance of pyrograph art and development and growth of pyrograph career will generate more far-reaching social and economic benefits

3) Establish a complete inheritance mechanism: The key to protection of traditional handicrafts is the "inheritance and development", and the core of inheritance and development is the mechanism established around inheritors and their heritage activities. It can be said that if there were no inheritors and their heritage activities, the traditional handicrafts will certainly perish, and only when the inheritors and heritage mechanism are well protected can the traditional handicrafts be well continued and developed. According to the active characteristics of traditional handicrafts, to carry out active protection to it is an important feature in the protection work. Therefore, the establishment of inheritance and protection mechanism and active protection principle are important links of the protection of traditional handicraft.

4) Broaden the source of protection funds: The protection of traditional handicraft is a social public welfare undertaking. To solve financial problems, we must first increase the financial capital investment, especially the central and 
provincial financial capital investment. At the same time, social capital investment should be encouraged. Clarify the fields that social capitals can enter and the management specifications, clarify the responsibilities of government departments and social forces, encourage and regulate the participation of social forces in the protection of traditional handicrafts, and establish a long-term mechanism for the protection and utilization of traditional handicrafts.

5) Enhance public awareness and enthusiasm of participation in inheritance: The driving force of traditional handicraft inheritance comes from the public, and the public participation in inheritance and protection directly reflects the level of a country's overall cultural inheritance consciousness, embodies a country's level of sustainable development. At present, China's public participation in the protection of traditional handicrafts is low, and it is very urgent to improve the public awareness of participation in the protection of inheritance.

\section{The DeVElopment Strategy Of The Pyrograph CRAFT In COSTUME DESIGN UNDER THE BACKGROUND OF ECONOMIC DEVELOPMENT IN HENAN PROVINCE}

\section{A. The Expansion of the Ideas of Costume Design}

Art design needs creativity, and art design with no creativity ahs no vitality, and will eventually be eliminated by the time, so is the costume design. Creative thinking has two layers of meaning: the first is creativity, expressed as the subjective reflection of objective things; the second is idea, expressed as the thinking activities of objective things. Accurately, creative thinking is the new idea different from the past generated by people through relevant analysis and comprehensive comparison during the process of discovering and understanding things according to their own basic knowledge and relevant experience.

\section{B. Inheritance and Innovation of Traditional Pyrograph Materials}

Selection of the material shall meet the needs of the theme ideas. The material is a complementary part of the subject content, which must be helpful in creating a typical meaning and typical environment, the most able to explain and extend the theme idea of the picture. Improper selection of material will undermine the ideological level of the theme. Material shall be refined and purified in use, but not the more the better. Do not put all the material related the theme in the picture. Layout should be reasonable. The background is generally arranged behind the main body of the picture. In specific use, the selected scene and the main body will also be extended to its left or right in connection, or even intertwine with each other and penetrate, at this time, we must pay attention to the primary and secondary relationship of the picture structure.

\section{Establish Scientific Research, Creation and Education Base}

We can try to centralize fairly well-developed education and complete education system within a certain area, and play a dominant or base role in culture, economy, production, technology of the Central Plains region. Divide a geographical combination of education according to their functions. The construction of the project shall rely on the support of the financial, material and human resources of the whole country and relevant areas. After the completion of the project, it will give full play to the highly-centralized scientific research ability and teaching, technological advantages, provide scientific research achievements, technology, cadres and experience for other regions, and promote the economic and cultural development of newly developed and backward areas. Its scope, structure, influence and the formation condition are similar educational center, educational area and educational hub, because in general, the educational base is the educational center, the education concentration area or educational hub.

\section{The Innovative Design Practice Based On Inheritance}

People often have a curious or hostile attitude towards new things. They need to gradually form an understanding of new things while understanding and contacting with them. They are often more prone to feeling close to the traditional form of things of their nation, and prefer to explain the essence and meaning of new things via the things that they have understood similar to the traditional culture. Therefore, if the idea of combining traditional elements and innovative design is blended into the product design, it is bound to generate innovative design products traditional cultural characteristics that people are more willing to accept, and will also be more conducive to speed up the leap from "Made in China" to "Created by China".

\section{CONCLUSION}

The pyrograph craft is a treasure for Nanyang, Henan and the Central Plains folk culture, with a long history and a wide foundation of the masses, whose cultural value has outdistanced the paper cutting itself. Since ancient times, the pyrograph craft's modeling methods have been embodying the rich design ideas of people, marked with the traces of human design ideas. It is in complete harmony with design, which difficult to distinguish. In the face of the rich national cultural resources, we can re-understand and re-excavate it from multiple levels and multiple angles, and accurately grasp the profound Central Plain cultural deposits and the connotation of the Central Plain aesthetic spirit through the deep analysis of the pyrograph craft, which has a huge impetus to the performance of modern costume design.

Today, with the development of science and technology and the integration of world economy, how to integrate the old local historical culture into more modern product design, bring more elements to prove our own ethnic identity and regional characteristics to the modern life increasingly internationalized and unified; blend fresh and modern elements into the local traditional culture body, so as to make our gradually faded and withered traditional culture and regional culture regain vitality and glory. 


\section{REFERENCES}

[1] Dong Jiqun, Song Chunlan. Folk craft [M]. Tianjin: Tianjin People's Publishing House, 2010

[2] Wang Guanying. Ancient Chinese Folk Craft [M]. Beijing: Chinese Cultural History Series, 2007

[3] Wang Haixia. Folk handicraft [M]. Beijing: China Social Press, 2011

[4] Li Yan. Reappearance and reconstruction - the contemporary nature of traditional folk craft [M]. Yunnan: Yunnan University Press, 2011

[5] Lu Yongxiang. Complete Works of Traditional Chinese Craft [M]. Henan: Henan Education Press, 2007.

[6] Ai Xiuqi. Chinese pyrography techniques [M]. Tianjin: Tianjin People's Publishing House, 2010. 